\title{
Ultrasonic exfoliation of carbon fiber: electroanalytical perspectives
}

\author{
Charnete Casimero $^{1}\left[\right.$ Catherine Hegarty $^{1} \cdot$ Ruairi J. McGlynn $^{1} \cdot$ James Davis $^{1}$
}

Received: 7 June 2019 / Accepted: 2 December 2019 / Published online: 30 January 2020

(c) The Author(s) 2019

\begin{abstract}
Electrochemical anodisation techniques are regularly used to modify carbon fiber surfaces as a means of improving electrochemical performance. A detailed study of the effects of oxidation $(+2 \mathrm{~V})$ in alkaline media has been conducted and Raman, XPS and SEM analyses of the modification process have been tallied with the resulting electrochemical properties. The co-application of ultrasound during the oxidative process has also been investigated to determine if the cavitational and mass transport features influence both the physical and chemical nature of the resulting fibers. Marked discrepancies between anodisation with and without ultrasound is evident in the C1s spectra with variations in the relative proportions of the electrogenerated carbon-oxygen functionalities. Mechanisms that could account for the variation in surface species are considered.
\end{abstract}

\section{Graphic abstract}

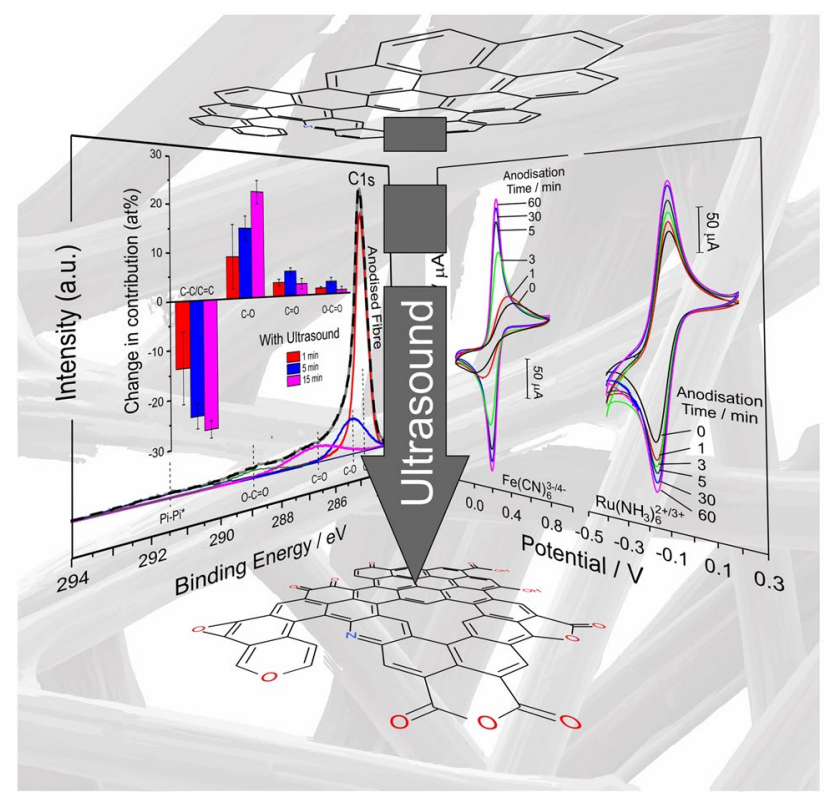

Keywords Carbon fiber $\cdot$ Electrode $\cdot$ Surface treatment $\cdot$ Anodisation $\cdot$ Ultrasound $\cdot$ XPS

Electronic supplementary material The online version of this article (https://doi.org/10.1007/s10800-019-01379-y) contains supplementary material, which is available to authorized users.

Charnete Casimero

casimero-c@ulster.ac.uk

1 School of Engineering, Ulster University, Jordanstown BT37 0QB, Northern Ireland

\section{Introduction}

Carbon is the principal electrode material in a vast number of electrochemical applications and its ubiquity can be attributed to a range of factors: diversity of physical form, rich interfacial chemistry and the relatively inexpensive cost with which the electrodes can be produced [1]. Carbon cloth 
electrodes, in particular, have risen to considerable prominence in recent years as they typically consist of an interpenetrating fiber matrix whose macro porosity and extensive surface area have been found to be highly advantageous in energy applications [2-6] and industrial water treatment [7-10]. Such electrode geometries are also finding favour within the various biosensing communities where the fiber network can serve as a host for bacterial species [4, 11, 12] or a framework for the immobilisation of enzymes [13, 14]. Polyacrylonitrile (PAN) fibers are the most common precursor $(>90 \%)$ but there has been considerable interest in other synthetic and bio-based systems [15-18]. Carbonisation of the spun polymer results in the production of fibers and, it is little surprise that both the mechanical and electrochemical properties of the fibers can be highly dependent on the nature of the preparation methods and subsequent processing treatments. It is usual to find that modification of the fibers through either chemical, plasma or electrochemical means is performed in order to improve their performance and, as such, an extensive literature base on surface treatments has arisen in recent years $[19,20]$.

The modification of carbon fibers has a long history and originated more from the need to improve their structural performance than their electrochemical properties [21, 22]. Carbon fibers are core components within composite matrices intended for high load bearing applications where high tensile strength, stiffness and low density are among the key attributes necessary for such applications [15, 16, 19]. Their reinforcement performance is often dependent upon the interfacial bonding strength between the fibers and the resin matrix [19, 23, 24] however, unmodified carbon fibers tend to possess a relatively featureless surface in terms of chemical functionality and physical morphology, both of which can compromise the mechanical properties of the composite $[20,25]$. Surface modification arose largely as a means of addressing these issues through generating a greater range of active functional groups and increasing surface roughness that could more effectively engage in interlocking the fiberresin composite. The influence of various types of surface treatment on the mechanical properties of carbon fiber and their influence on composite performance have been comprehensively reviewed $[19,20]$.

It must be noted that many of the chemical alterations to the carbon surface can also dramatically improve the performance and versatility of the carbon fibers when applied as electrode materials. While a large range of treatments have been investigated $[19,20]$, the end outcome is normally the oxidation of the surface to increase the variety of carbonoxygen functional groups and their respective concentrations [8, 26-28]. A summary of the different types of oxygen functionality that can arise as a consequence of surface oxidation is highlighted in Fig. 1 but, it should be noted, these are indicative only of the base functionality and that a

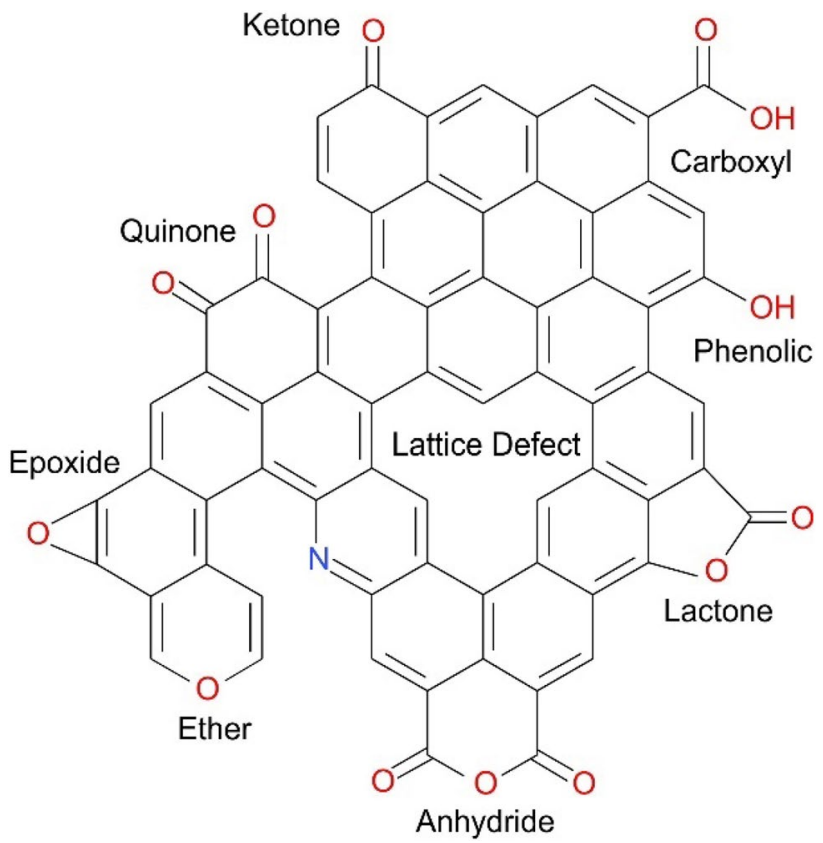

Fig. 1 Summary of the different functional groups present on the surface of carbon fiber (adapted from [29])

spectrum of forms will be generated as the graphitic plane is remodelled [29, 30]. In many respects, the variety of oxygen functionality reported post modification are analogous to those identified in graphene oxide fragments [31] albeit fixed to the body of the fiber structure.

An example of nitrogen functionality has also been included in Fig. 1 as there will inevitably be trace components (i.e. pyridinic and pyrrolic) within the graphitic planes. These can be attributed (in the absence of an exogenous nitrogen source) to the incorporation of PAN nitrogen into the graphitic lattice during carbonisation process used to form the fibers [18]. The nitrogen component will be minor in unmodified fibers with $\mathrm{sp}^{2}$ carbon being the predominant species and, it is the oxidative destruction of the latter that gives rise to the carbon-oxygen functionality. A large number of treatment options have been pursued [19], such as electrochemical oxidation (anodisation) which is well established as an effective technique for the generation of oxygen functional groups as well as enabling the etching of the surface [8, 26-28]. It is now commonplace for carbon fiber electrodes, whether discrete fibers, bundles, mats or cloths, to be electrochemically treated prior to further application in order to improve electron transfer kinetics $[11,12,28]$.

While it is recognised that the surface functionality increases with increasing charge, the simultaneous application of electrochemical oxidation and ultrasonic activation has yet to be explored. The macro / micro streaming processes and cavitation events arising from the application of ultrasound can significantly influence electrochemical 
processes [32, 33] and have been shown to operate in porous as well as planar substrates $[34,35]$. It could be envisaged that these same effects could impact on the anodisation processes occurring at the carbon fiber through increasing the penetration of the electrolyte through the network, removing bubbles and expediating delamination of mechanically weak carbonaceous layers [36]. It could be anticipated that the combination of electrolytic processes, acoustic streaming and cavitation effects could enhance the exposure of fresh graphitic layers, increasing edge plane defects and alter the respective functional group populations.

\section{Experimental details}

\subsection{Materials and instrumentation}

All chemicals were obtained from Sigma-Aldrich, were the highest grade available and were used without further purification. Britton Robinson buffers (acetic, boric, and phosphoric acids, each at a concentration of $0.04 \mathrm{M}$ and adjusted to the appropriate $\mathrm{pH}$ through the addition of sodium hydroxide) were used throughout unless otherwise specified. Electrochemical analysis was carried out using a micro Autolab (Type III) computer controlled potentiostat (Eco-Chemie) with a standard three-electrode configuration in which the carbon fiber electrode was used as the working electrode with platinum and a $\mathrm{Ag} \mid \mathrm{AgCl}$ half cell (3M $\mathrm{NaCl}$, BAS Technicol UK) acting as counter and reference respectively. Sonoanodisation experiments were conducted by immersing the electrochemical cell in a conventional laboratory ultrasonic cleaning bath (operating at $40 \mathrm{kHz}$ ).

A Kratos Axis Ultra DLD Spectrometer was used to quantify surface composition and acquire X-ray photoelectron spectroscopy (XPS) spectra. Spectra were analysed using monochromated $\mathrm{Al} \mathrm{K} \alpha \mathrm{X}$-rays ( $\mathrm{hv}=1486.6$ electron volts $(\mathrm{eV}))$ operating at $15 \mathrm{kV}$ and $10 \mathrm{~mA}(150 \mathrm{~W})$. During analysis, a hybrid lens mode was used (electrostatic and magnetic) with a $300 \mu \mathrm{m} \times 700 \mu \mathrm{m}$ analysis area and a takeoff angle (TOA) of $90^{\circ}$ with respect to the sample surface. Wide energy survey scans (WESS) were collected across a range of -5 to $1200 \mathrm{eV}$ binding energy (BE), with a pass energy of $160 \mathrm{eV}$ and step size of $1 \mathrm{eV}$. High-resolution spectra were collected with a pass energy of $20 \mathrm{eV}$ with a $0.05 \mathrm{eV}$ step size, a scan width of $25 \mathrm{eV}$, a dwell time of 150 milliseconds and at least 3 sweeps to reduce the signal noise. A Kratos charge neutraliser system with a filament current of $1.8 \mathrm{~A}$ and a charge balance of $3.6 \mathrm{~V}$ and a filament bias of $1.3 \mathrm{~V}$ was used for all samples. Charging effects on the $\mathrm{BE}$ positions were adjusted by setting the lowest $\mathrm{BE}$ for the $\mathrm{C} 1 \mathrm{~s}$ spectral envelope to $284.8 \mathrm{eV}$, which is commonly accepted as adventitious carbon surface contamination. Three measurements were analysed per sample, with a
Shirley background subtracted from each XPS spectra. The peak areas of the most intense spectral lines for each elemental species were used to determine the percentage atomic concentration. Peak fitting of high-resolution spectra was carried out using Casa XPS software.

Raman spectra were obtained using a Horiba LabRAM 300 spectrometer employing a HeNe laser [632 nm, 50 X optical lens, spot approx. $30 \mu \mathrm{m}, 10 \%$ filter, laser power 2.59 $\mathrm{W}(25.9 \times 10 \%)]$. The carbon fiber samples were analysed over $100-3500 \mathrm{~cm}^{-1}$ conduced in 5 slices (energy per slice $38.85 \mathrm{~J}$ ) to cover the range with 5 spots per sample.

\section{Results and discussion}

\subsection{Preliminary electrochemical evaluation}

Given the variety of carbon forms used in the construction of electrodes, it is little surprise that there will be an equally large range of surface structures. In the simplest terms, graphitic carbon possesses two structural features-the basal and edge planes-which can exert markedly different electrochemical properties. Both planes are common to carbon fiber with the basal plane (the hexagonal surface running parallel to the graphite layer) being the predominant form in unmodified fiber surfaces. Their respective influence on electron transfer kinetics depends on the nature of the redox couple under investigation with ferrocyanide and ruthenium hexamine often used as two contrasting redox probes. Ferrocyanide is known to exhibit inner sphere behaviour and is highly sensitive to the nature of the surface whereas ruthenium hexamine, an outer sphere complex, is less perturbed by differences in structural form. In the case of ferrocyanide, carbon surfaces in which edge plane sites dominate are well known to facilitate faster electron transfer than those that are predominantly basal plane $[37,38]$. This is highlighted in Fig. 2a where the response of the unmodified carbon fiber (largely basal plane) towards ferrocyanide exhibits irreversible behaviour $(\Delta \mathrm{Ep}=300 \mathrm{mV})$ and stands in contrast to the reversible profile recorded for ruthenium hexamine at the same electrode (Fig. 2b).

The process of anodisation, with or without the application of ultrasound, leads to significant remodelling of the graphitic plane with a considerable increase in both carbonoxygen functionality and carbon defects as highlighted in Fig. 1. Cyclic voltammograms detailing the response of a carbon fiber electrode towards ferrocyanide and ruthenium hexamine (each at $2 \mathrm{mM}$ in $0.1 \mathrm{M} \mathrm{KCl}$ ) after various anodisation treatments are detailed in Fig. 2a and b respectively. Anodisation can be seen to dramatically improve the response to ferrocyanide with the initial irreversible behaviour at the unmodified fiber quickly changing to a reversible system. The peak separation decreases markedly 

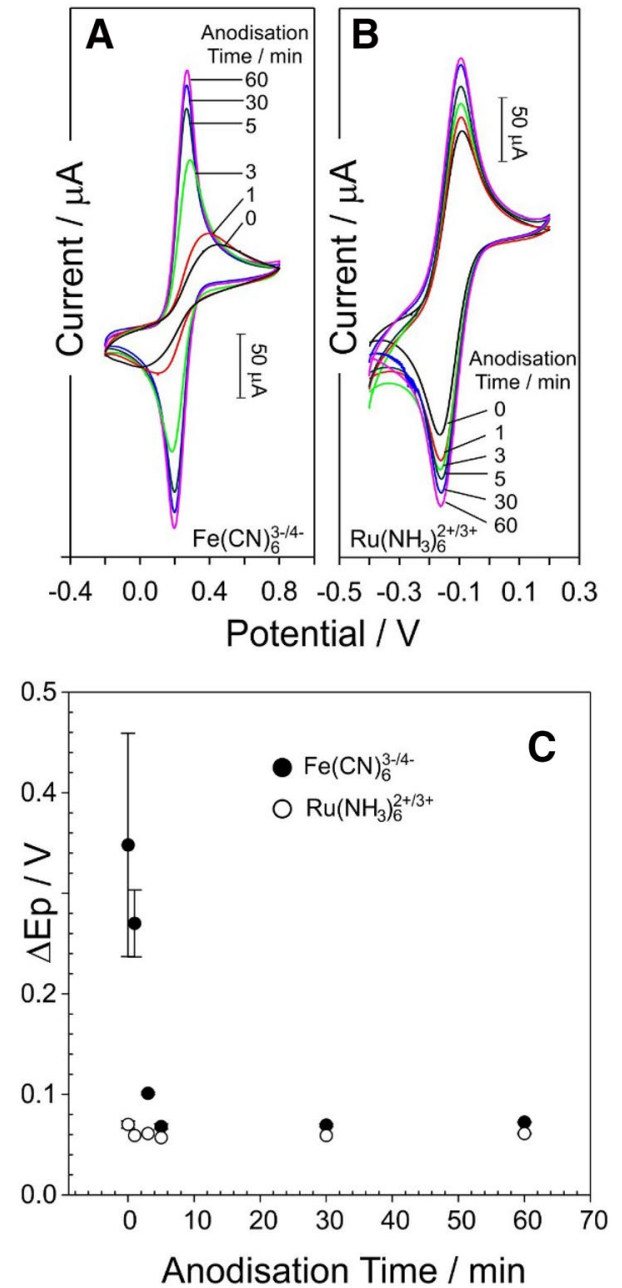

Fig. 2 Cyclic voltammograms detailing the response of carbon fiber electrodes to a ferrocyanide $(2 \mathrm{mM}, 0.1 \mathrm{M} \mathrm{KCl})$ and b ruthenium hexamine $(2 \mathrm{mM}, 0.1 \mathrm{M} \mathrm{KCl})$ after various pre-treatment times in the absence of ultrasound. $\mathbf{c}$ Influence of anodisation time on the peak separation of ferrocyanide and ruthenium hexamine. Scan rate: 50 $\mathrm{mV} / \mathrm{s}$

as the anodisation time is increased and approaches classical reversibility at electrodes which have been anodised for $5 \mathrm{~min}$ or more as indicated in Fig. 2c. Elucidating the role of surface oxides on electron transfer kinetics has been complicated through conflicting reports. Oxidised carbon electrodes have regularly been reported to improve electron transfer kinetics for a variety of species $\left(\mathrm{Fe}(\mathrm{CN})_{6}{ }^{3-14-}\right.$, $\mathrm{Eu}^{2+/ 3+}, \mathrm{Fe}^{2+/ 3+}$ and $\mathrm{V}^{2+/ 3+}$ ) and can increase by a factor of 500 post anodisation $[39,40]$. Yet for ferrocyanide, there have also been some reports that suggest carbon oxides play only a minor role (factor of 2-3) [41].

Electron transfer to ferrocyanide is known to be highly surface sensitive $[42,43]$ and it is likely that the increased population of oxygen functionalities and edge defects arising as a consequence of the anodisation process serve, in combination, to improve the performance. Support for this has been provided by the work of Gooding et al on the response of ferrocyanide at single walled carbon nanotubes (SWCNTs) [44]. The latter can essentially be considered as cylindrical tubes of graphite possessing both basal and edge plane sites [37, 45]. Oxidation of the SWCNT ends with nitric acid leads to the production of oxygen functional groups (predominantly carboxyl) and was found to significantly improve the electron transfer kinetics of the ferrocyanide. Similarly, Compton and co-workers demonstrated that the electron transfer kinetics of ferrocyanide at basal plane pyrolytic graphite, a surface known to exhibit poor ferrocyanide responses, could be greatly improved through the immobilisation of multi-walled carbon nanotubes (MWCNTs) [43]. Again, it is noteworthy that the exposed ends of the MWCNTs possessed a high proportion of oxygen functionality. The presence of carbon-oxygen functionality is not the sole factor in improving the electrode performance in the case of ferrocyanide, as Compton et al. have demonstrated that freshly cleaved edge plane pyrolytic graphite (in which oxygen functionality is presumed to be minor) also exhibit fast electron transfer and that, in contrast to previous assumptions, exposure of the carbon surface to air impedes the latter [43]. It should be noted however that the interaction of freshly cleaved carbon with air may not necessarily lead to the same carbon-oxygen functionality generated through more vigorous oxidative treatments (chemical or electrochemical).

The co-application of ultrasound/anodisation leads to the attainment of reversibility for the ferrocyanide couple at the fiber electrode quicker than simply employing electrochemical oxidation alone. This is exemplified by comparing the voltammograms detailing the responses to the ultrasonically assisted anodised fiber and an electrode pre-treated for the same duration in the absence of ultrasound (Fig. 3).

Beyond pre-treatment times of $5 \mathrm{~min}$, little difference between the profiles of electrodes anodised with or without the addition of ultrasound were found. Both exhibited similar peak separations and peak heights (akin to those highlighted in Fig. 2c). The preliminary assessment from this data would suggest that the ultrasound exerts a kinetic effect on the electrode modification rather than any significant structural variation however, it is likely that more factors, as noted in following sections, underpin the response.

Examination of the ruthenium hexamine responses (Fig. 2b) highlight quite contrasting behaviour to those observed with ferrocyanide. The former is a well established outer sphere complex which is relatively insensitive to the carbon fiber surface chemistry and exhibits reversible behaviour at the unmodified electrode, with the peak separation and peak height ratio unaffected by anodisation. It can be observed however that the peak magnitude increases with anodisation time (also observed with the ferrocyanide) and can be attributed to slight increases in the electrode area. 


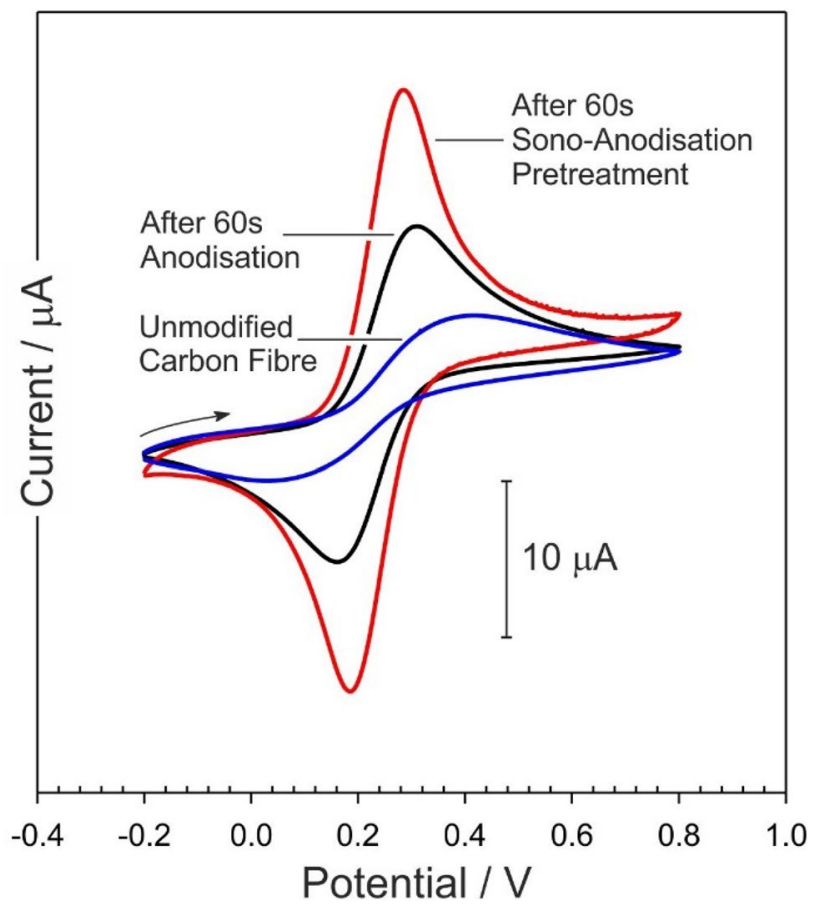

Fig. 3 Cyclic voltammograms detailing the response of carbon fiber electrode towards ferrocyanide $(2 \mathrm{mM}, 0.1 \mathrm{M} \mathrm{KCl})$ after anodisation with and without the application of ultrasound. Scan rate: $50 \mathrm{mV} / \mathrm{s}$

Delamination of the outer surfaces of the fiber with increasing anodisation time serve to increase the accessible electrode area. Examination of the scan rate responses of both ferrocyanide and ruthenium with anodisation time was also conducted to determine if the remodelling of the carbon surface led to defects that could entrap the redox probes. Linear responses were observed with the square root of scan rate confirming that both probes exhibited conventional diffusion behaviour.

\subsection{Raman spectroscopy studies of treated fibers}

Raman spectroscopy of the carbon fiber surface pre and post modification was used as an initial probe of surface defects and representative spectra for a fiber mat modified without the application of ultrasound are detailed in Fig. 4a. The first order spectra of the fibers contain a number of prominent peaks: $1350 \mathrm{~cm}^{-1}$ (D band), $1580 \mathrm{~cm}^{-1}$ (G Band) and 1610 $\mathrm{cm}^{-1}$ ( $\mathrm{D}^{\prime}$ band). While the $\mathrm{G}$ band is associated with the graphitic in-plane vibration with an $\mathrm{E}_{2 \mathrm{~g}}$ symmetry, the $\mathrm{D}$ and D' bands are widely attributed to arise from the presence of defects within the lattice and are an indicator of disorder and are consistent with previous studies of oxidised carbon fiber [19, 36, 46]. It can be seen from Fig. 4a that the D and D' bands increase with increasing anodisation time and can be attributed to increased population of in-plane heteroatoms, grain boundaries and aliphatic components. The oxidation
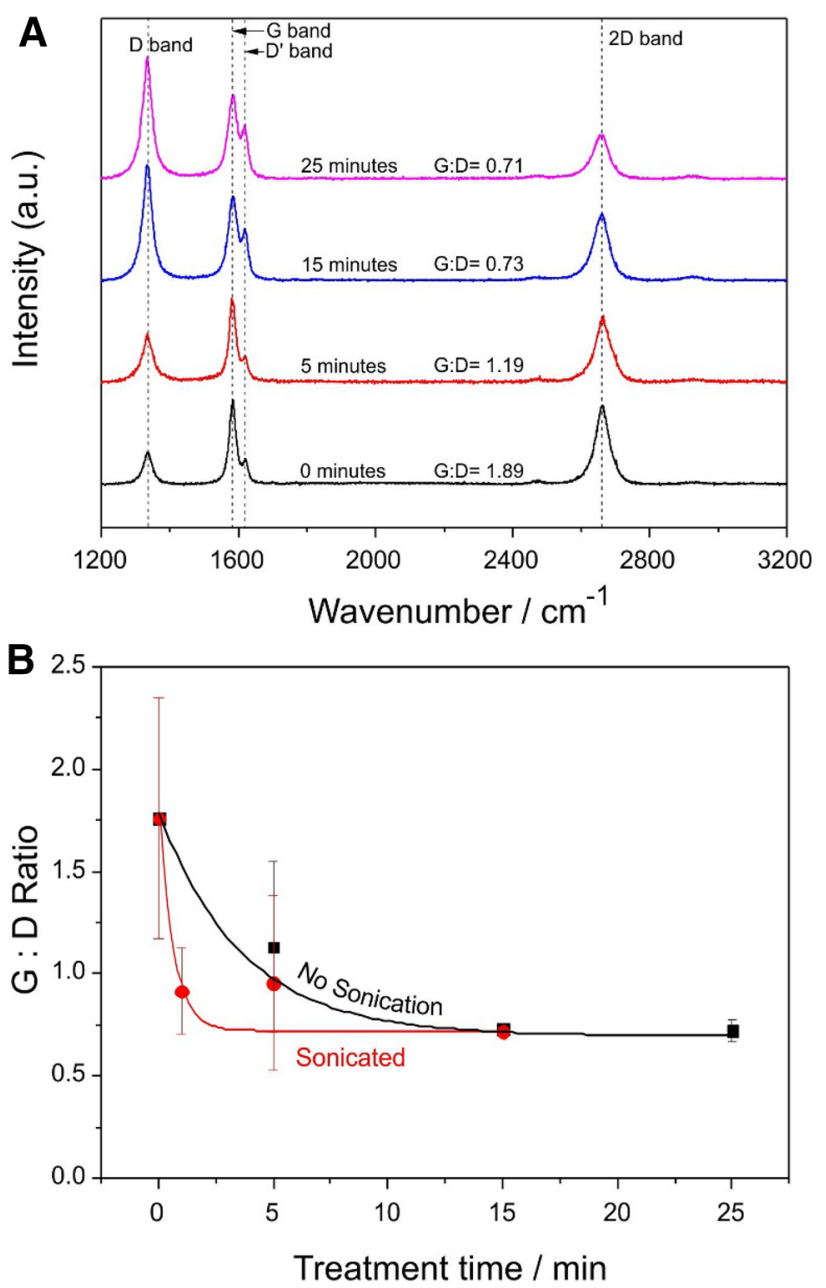

Fig. 4 a Raman spectra of the carbon fiber surface before and after various anodisation periods in the absence of ultrasound. b Influence of anodisation with and without ultrasound on the degree of disorder within the carbon fiber lattice.

process, as indicated in Fig. 1, increases the incorporation of oxygen and the production of defects-both of which reduce the symmetry of a quasi infinite graphite plane.

Comparison of the ratio of the $\mathrm{D}$ and $\mathrm{G}$ bands for each treatment can give some insights into the effect anodisation has on the carbon structure. It can be seen from Fig. 4b that the application of ultrasound during the anodisation process speeds up the disordering of the graphitic lattice but does not, ultimately, lead to any increase in disorder beyond that achievable with the silent anodisation alone. This observation is similar to the electrochemical investigations where ultrasound assisted anodisation was found to simply increase the speed at which the ferrocyanide response became reversible (Fig. 3). The imposition of the anodic potential $(+2 \mathrm{~V})$ lead to the generation of oxygen bubbles at the electrode interface and, it can be envisaged that their adherence to the electrode will effectively 
block access of electrolyte and reduce the efficiency of the surface treatment. This effect could be expected to be exacerbated in a 3D fiber network where the interpenetrating strands serves to entrap the bubbles. The application of ultrasound during the anodisation process could be expected to aid removal of the bubbles, effectively degassing the electrode interface [32]. Moreover, the cavitation effects should also increase mass transport of fresh electrolyte $(\mathrm{NaOH})$ to the electrode and further increase the rate of modification.

\subsection{Contact angle measurements}

The hydrophobicity of the unmodified fiber was investigated through the use of contact angle measurements. As expected, the unmodified fiber, being largely graphitic in nature exhibited considerable hydrophobicity $\left(>110^{\circ}\right)$. Contact angle measurement and representative images for each of the samples as a function of anodisation process are detailed in Fig. 5. Anodisation of the surface greatly improved surface wetting and it could be envisaged that the increased population of hydrophilic $\mathrm{C}-\mathrm{OH}$ and carboxyl functionality would be among the main drivers $[6$, 47]. The co-application of ultrasound during the anodisation process again appears to exert a kinetic effect with a much more extensive wetting when compared to the silent process. It is likely that the physical factors associated with cavitation (discussed in the previous section) are again responsible for the greater increase in hydrophilicity.

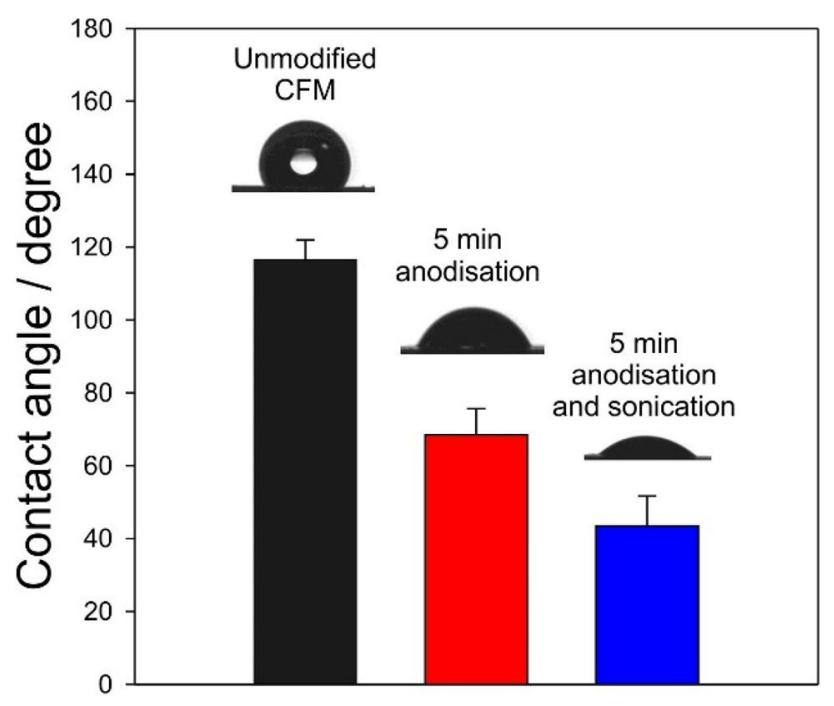

Fig. 5 Contact angle measurements for carbon fiber before and after anodisation with and without the co-application of ultrasound. Representative images highlighting the extent of surface wetting for each sample has also been included. (Based on 6 measurements per sample type)

\subsection{Influence of ultrasound on fiber morphology}

The Raman data, while implying that there is no significant increase in disorder at the molecular scale with the application of ultrasound at long anodisation times over that obtained under silent conditions, belies the fact that there is significant change on the macro scale. Considerable deterioration in the physical condition of the fibers after the application of the ultrasonic-anodisation processes was observed. Scanning electron micrographs detailing the effect of anodisation (with and without ultrasound) at various treatment times are compared in Fig. 6. The unmodified fiber (6a) has notable striations along the longitudinal axis of the fibers and is a characteristic of the fiber production process. Upon commencing anodisation (5 min), the striations become more pronounced and erosion of the outer sheath surface is clearly visible (6b). As the anodisation time is lengthened, the degree of damage to the fiber is notably increased and delamination of graphitic planes/shards (6c) occurs. It is inevitable that such processes are facilitated by the evolution of oxygen at the electrode from the electrolytic processes where the manifestation of bubbles under partially delaminated regions further aid the physical removal of graphitic sheaths.

It is notable that in the absence of ultrasound, although deterioration of the individual fibers can be observed, the bulk structure of the fiber network is largely preserved (6d). Narrowing of the fibers through erosion/delamination occurs (6e) and the process is greatly accelerated when ultrasound is applied. Comparison of the anodisation with and without ultrasound (6b-f, C-G, D-H) highlights substantially more damage occurring with the co-application of ultrasound. This is clearly seen when examining the bulk structures $(6 \mathrm{~d}-\mathrm{h})$ where the sustained narrowing of the fibers leads to the mechanical failure of the network (6h). This stands in contrast to the Raman spectra where even at long anodisation times $(>15 \mathrm{~min})$ there is little difference between the two on the molecular scale.

\subsection{XPS studies of carbon-oxygen functionality}

Increasing the carbon-oxygen functionality through the process of electrochemical anodisation was confirmed through examining the $\mathrm{C} 1 \mathrm{~s}$ and O1s XPS spectra. The $\mathrm{C} 1 \mathrm{~s}$ spectra in Fig. $7 \mathrm{a}$ were deconvoluted into $\mathrm{C}=\mathrm{C} / \mathrm{C}-\mathrm{C}$, $\mathrm{C}-\mathrm{OH} / \mathrm{C}-\mathrm{O}-\mathrm{C}, \mathrm{C}=\mathrm{O}$ and $\mathrm{COOH}$ components representing the prime functional groups liable to arise as a consequence of the oxidation process (Fig. 1). Comparison of the spectra obtained after 5 min with the unmodified fiber (Inset Fig. 7a) reveals that there is an increase in the respective oxygen functionalities.

This is seen more clearly in the O1s spectra (Fig. 7b) where the initial oxygen peak attributed to carbonyl/ketone 


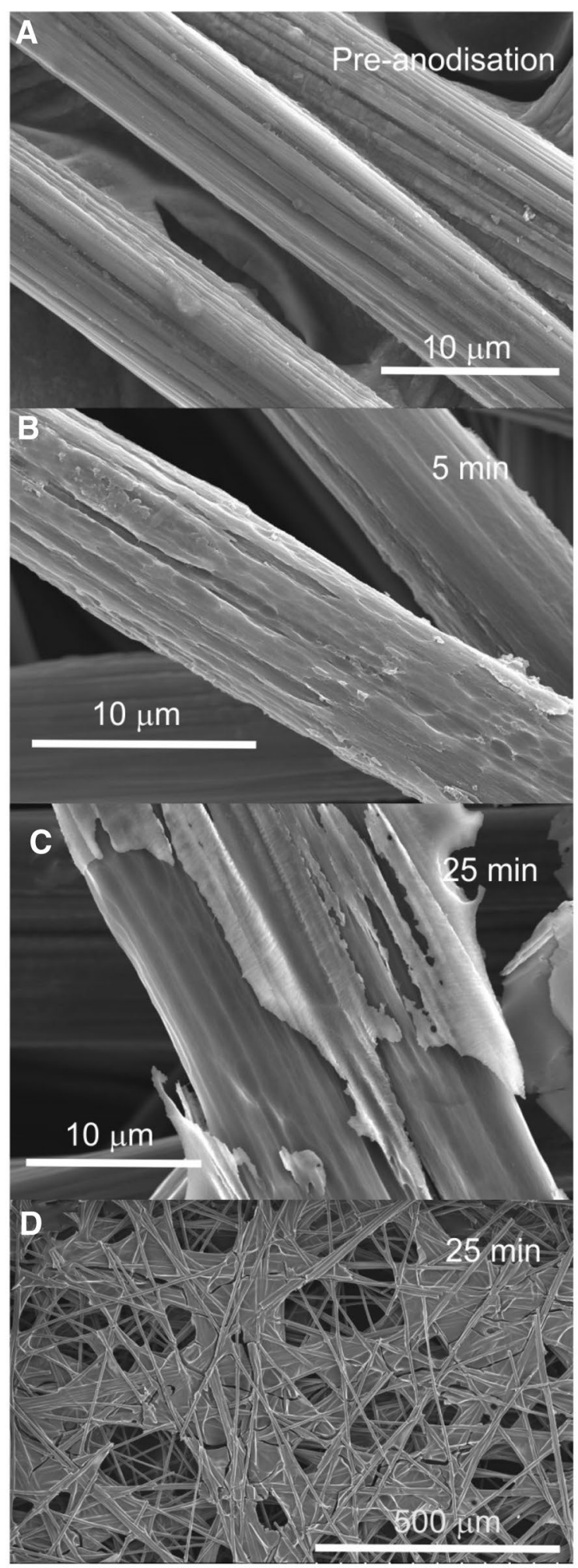

E

25 min + sonication
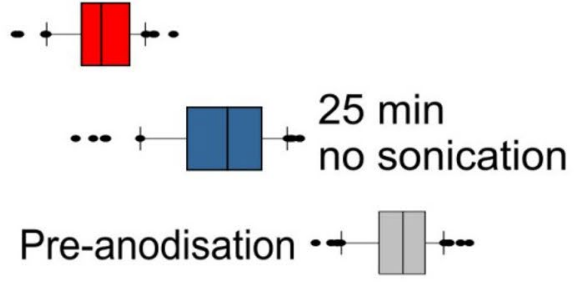

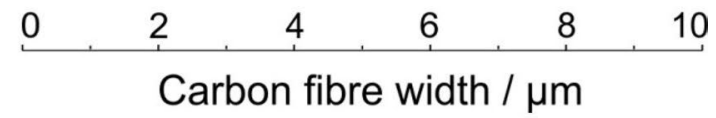

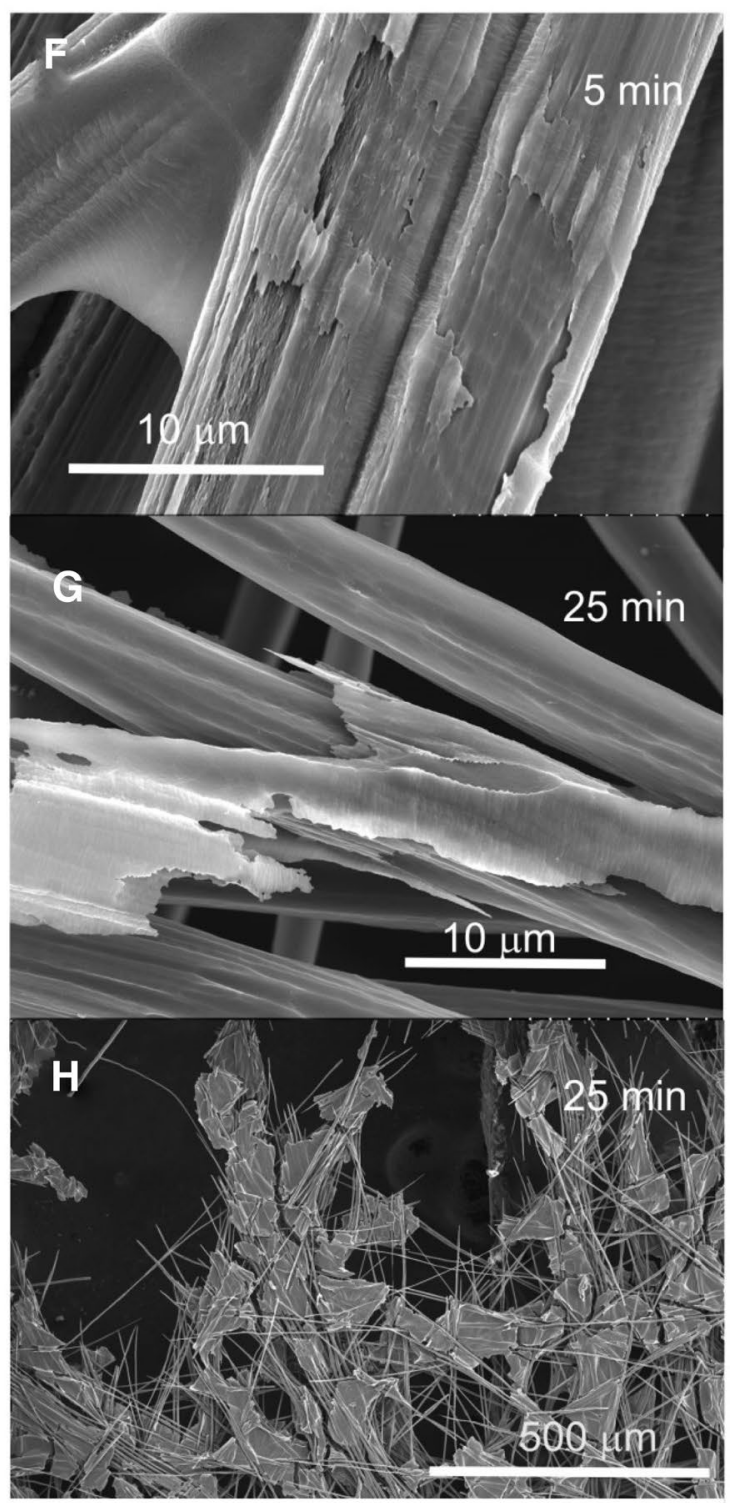

Fig. 6 Scanning electron micrographs detailing the surface morphology of the carbon fiber before (a) and after anodisation in the absence (b-d) and presence (f-h) of ultrasound. A comparison of the effect of anodisation on carbon fiber diameter $(\mathbf{e})$ is also presented $(\mathrm{N}=50)$ 

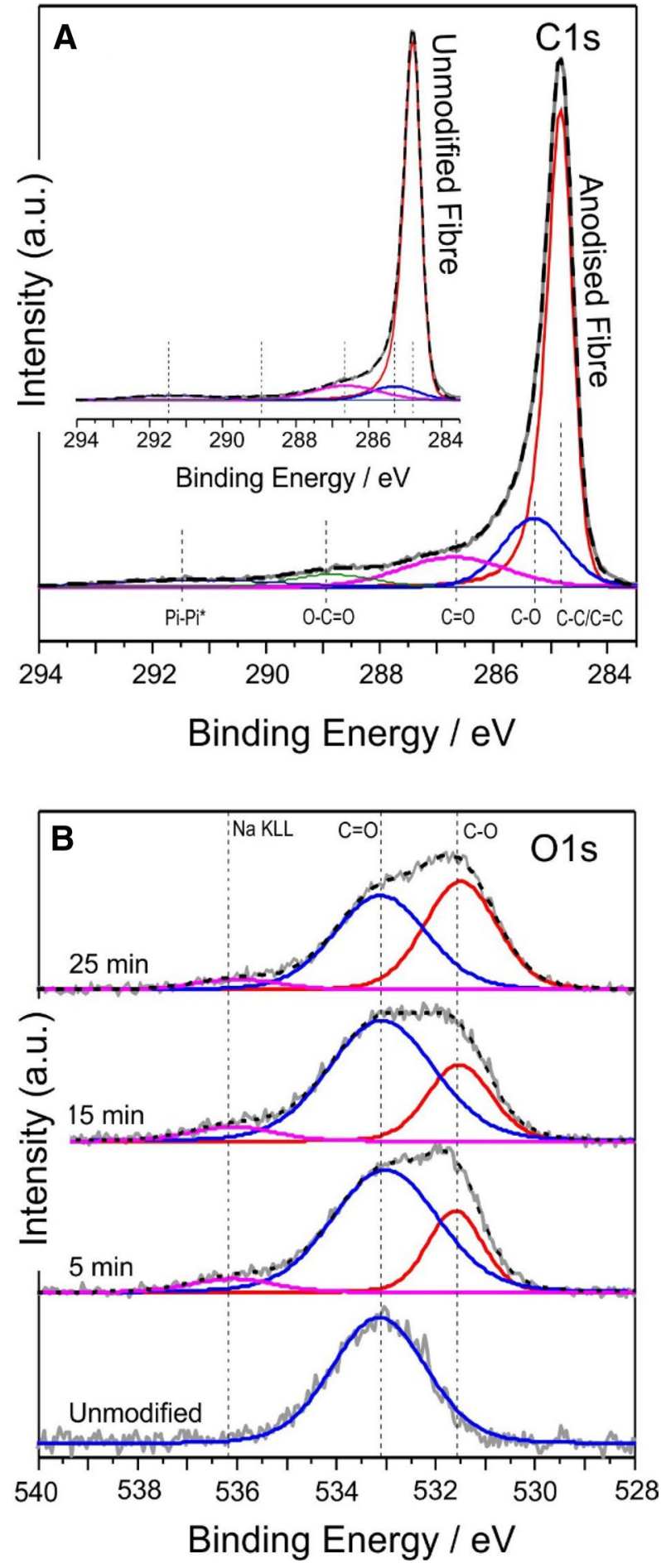

Fig. 7 XPS analysis of the C1s (a) and O1s (b) profiles before and after anodisation in the absence of ultrasound

groups is seen to split upon oxidation to the $\mathrm{C}-\mathrm{O}$ indicating an increase in phenolic functionality. Similar features in both $\mathrm{C} 1 \mathrm{~s}$ and $\mathrm{O} 1 \mathrm{~s}$ spectra were observed with the sonicated fibers however there were slight, but distinct, variations in the relative proportions of each grouping. A more quantitative
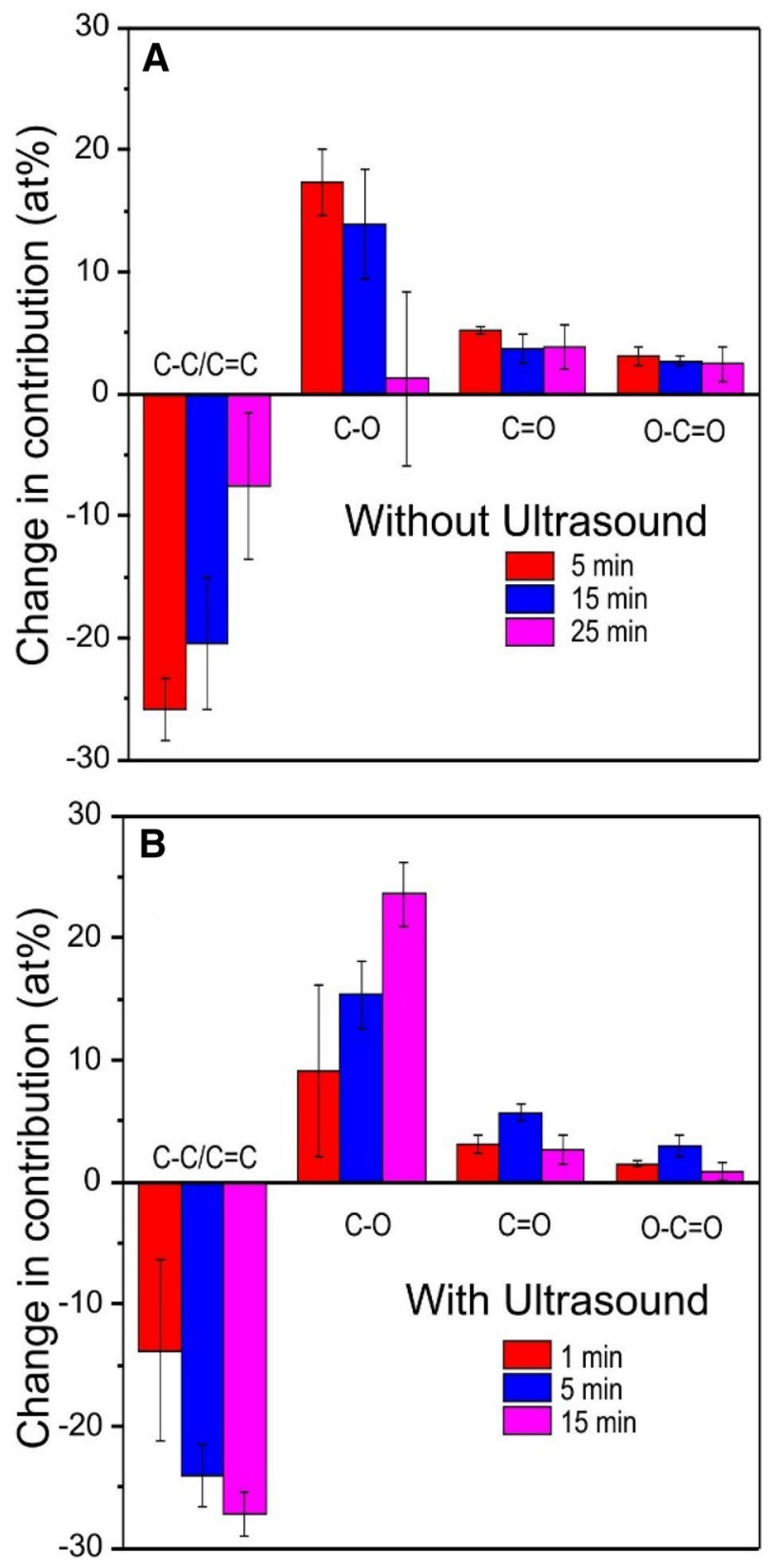

Fig. 8 Summary of the net changes in carbon functionality as a consequence of anodisation being conducted in the absence (a) and presence of ultrasound (b)

comparison between the anodisation process conducted with and without ultrasound is detailed in Fig. 8.

Examination of the deconvoluted $\mathrm{C} 1 \mathrm{~s}$ spectra recorded in the absence of ultrasound reveals that at the initial outset of the anodisation process, there is considerable degradation of the lattice with loss of $\mathrm{C}=\mathrm{C}$ functionality and the emergence of $\mathrm{C}-\mathrm{O}$ groups with relative minor amounts of carbonyl $(\mathrm{C}=\mathrm{O})$ and carboxyl $(\mathrm{COO})$ components. As the electrolysis continues, the latter remain almost constant but there is a sustained decrease in both $\mathrm{C}-\mathrm{O}$ formation and 
$\mathrm{C}=\mathrm{C} \mathrm{sp}{ }^{2}$ degradation. The latter requires a degree of caution in interpretation and it is possible to suggest a number of pathways through which to explain the observations. First, it is not possible to reliably discriminate between $\mathrm{sp}^{2}$ and $\mathrm{sp}^{3}$ signals in the deconvoluted spectrum. While $\mathrm{sp}^{2}$ carbon will be by far the predominant form of carbon in the unmodified fiber-oxidative destruction of the lattice, particularly over prolonged periods, could lead to an increase in aliphatic $\mathrm{sp}^{3}$ functional groups. Thus, the decrease in the $\mathrm{C}=\mathrm{C}$ component would be countered by the increase in the $\mathrm{C}-\mathrm{C}$ component, but as both XPS signals are separated by only $0.3 \mathrm{eV}$, the transformation of one to the other would mean little change in the observed/combined $\mathrm{C}-\mathrm{C} / \mathrm{C}=\mathrm{C}$ peak. An alternative and potentially complementary process could be attributed to the fact that over prolonged oxidation periods, exfoliation of the carbon sheath occurs (cf. Fig. 6c) which exposes new graphitic layers. Rather than the oxygen functionality increasing with time, the shedding of previously oxidised layers effectively resets the oxidation process with a fresh surface (largely $\mathrm{sp}^{2}$ ). The latter could be further compounded by the fact that the electrolytic process, under diffusion control, results in changes in local $\mathrm{pH}$ and thus, could effectively diminish the effectiveness of the oxidative modification process.

The ultrasound assisted anodisation process (Fig. 8b) results in markedly different outcomes from those observed with the simple anodisation procedure. As treatment time increases the degree of lattice transformation also increases with the destruction of the $\mathrm{sp}^{2}$ component and formation of $\mathrm{C}-\mathrm{O}$ functionality. It is possible that the kinetic influence observed earlier with the electrochemical and Raman investigations also has a part to play here. While it is clear that delamination occurs steadily at prolonged anodisation times in the presence of ultrasound (Figs. 6e-g), it could be expected that as soon as material is lost-it is immediately functionalised. The cavitational effects would also be expected to impact on the modification through delivering fresh electrolyte.

There is clearly some mechanistic discrepancy between the two approaches and, while it is most prominent with relative production of $\mathrm{C}-\mathrm{O}$ functionality, it is also noticeable with carboxyl groups. The production of the latter is minor in both cases, which, in itself, is of considerable significance given the role such groups have in the carbodiimide coupling of biological catalysts. There has generally been an assumption that the oxidation of carbon materials leads to a profusion of carboxyl groups which can be used to tether biological agents but, it is clear from these investigations, that while there is an increase, it is not the major product. The ultrasound assisted anodisation technique appears to generate even less and this could be attributed to some underlying mechanistic consideration or the steady removal of carbonaceous layers.

\subsection{Carbon-quinone electrochemistry}

The XPS investigations of the unmodified carbon fibers reveals that, even before modification, the graphitic layers are far from pristine and there is a variety of carbon-oxygen functionality. The presence of quinoid functionality on carbon has long been recognised and can be electrochemically observed through the application of more sensitive techniques such as square wave voltammetry [48]. The influence of anodisation time on the production of electrochemically accessible quinone redox groups is highlighted in Fig. 9. The voltammetric sweep commences at $-0.8 \mathrm{~V}$ which is sufficient to reduce the surface quinones to the hydroquinone form with reconversion to the former occurring between +0.1 and $+0.3 \mathrm{~V}$ as the scan progresses towards more positive potentials. It is clear from the shape of the voltammetric profile that the "peak" responses are in fact multicomponent and reflects the heterogeneity of the quinone groups on the carbon surface generated by a non-specific anodisation procedure.

Inspection of Fig. 8a reveals that the relative proportion of the $\mathrm{C}=\mathrm{O}$, one component of the quinone functionality, remains relatively constant irrespective of anodisation time. This observation contrasts the outcomes noted in Fig. 9 where there is a sustained increase in quinone redox activity with anodisation time. A possible explanation centres on the chemical nature of the quinone component. While

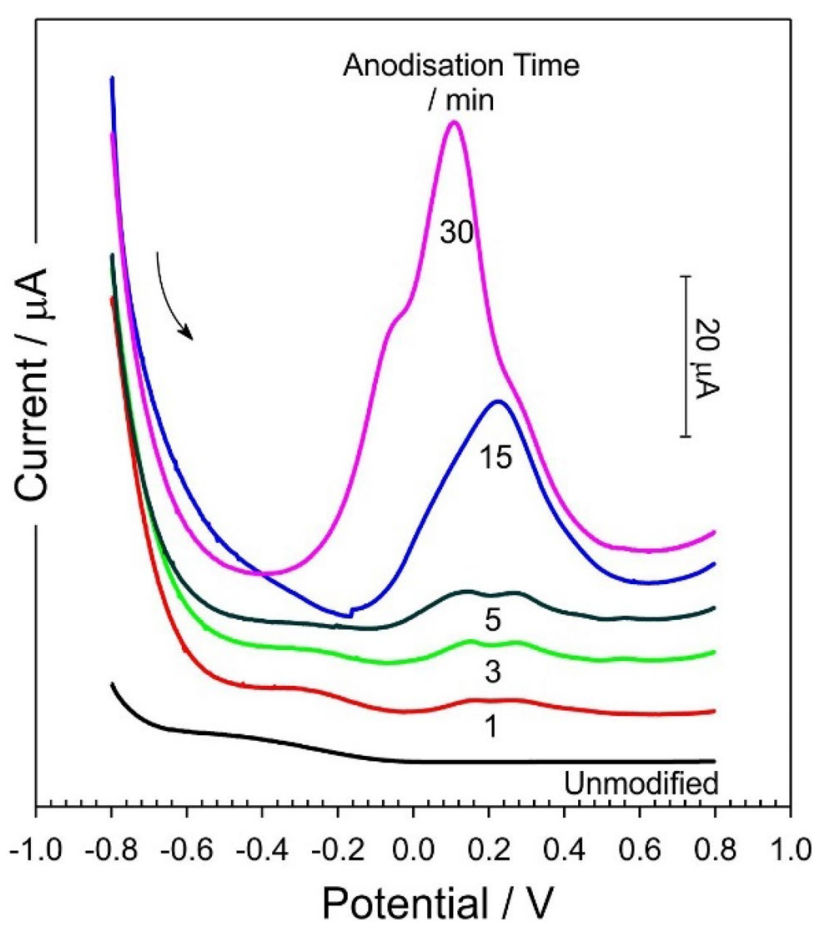

Fig. 9 Square wave voltammograms detailing the response of a carbon fiber electrode in $\mathrm{pH} 3$ Britton-Robinson buffer after various anodisation times in the absence of ultrasound. 
the oxidised quinone form exhibits the characteristic $\mathrm{C}=\mathrm{O}$ functional group, the reduced form is $\mathrm{C}-\mathrm{O}$ as indicated in Fig. 10a. Thus, the increase in quinone electrochemistry cannot be wholly matched with the ketone $\mathrm{C}=\mathrm{O}$ XPS concentration and rather, lies in the combination of the $\mathrm{C}-\mathrm{O}$ and $\mathrm{C}=\mathrm{O}$. It is also important to realise that $\mathrm{C}-\mathrm{O}($ or $\mathrm{C}=\mathrm{O})$ can also exhibit longitudinal quinone activity across the lattice (Fig. 10b) and do not necessarily have to be confined to the more simple 1,2 or 1,4 dihydroxy moieties (Fig. 10a).

\subsection{Alternative pre-treatment processes}

There has been intense interest in the modification of carbon fiber surfaces as well as other carbonaceous formats. These have attempted to alter the surface activation, pore size distribution and functionalisation with an extensive array of species [19, 20, 49]. In almost all cases, surface pre-treatment is critical and these include: chemical oxidation [50], oxygen plasma [14], gamma irradiation [14], spark discharge [51], thermal air oxidation [14, 52, 53], laser ablation [54] and various electrochemical techniques [55-57]. A brief summary of the more recent approaches are highlighted in Table 1.

Additionally, the grafting of carbon nanomaterials such as nanotubes, graphene, nanospheres and multifunctional nanocarbon composites have been investigated as a means of increasing the active surface of the fibers [56, 58]. Metal

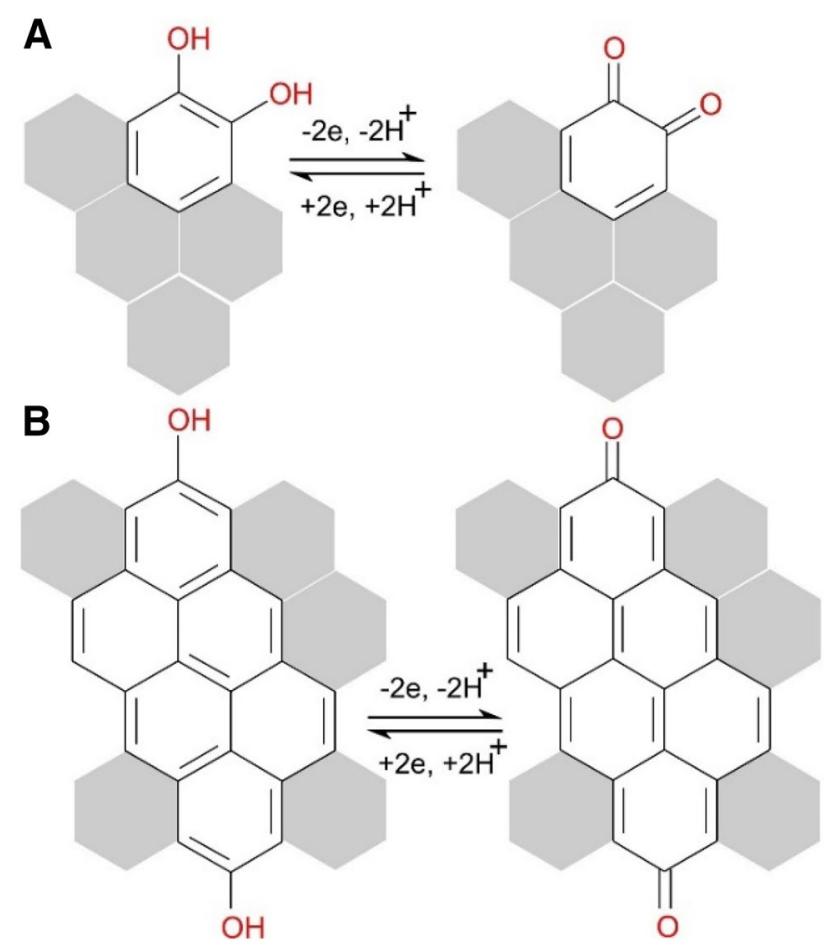

Fig. 10 Redox transition of different quinone species present on the surface of carbon fiber
Table 1 Common pre-treatment processes applied to carbon fiber electrodes

\begin{tabular}{lll}
\hline Pre-treatment process & Application & References \\
\hline Chemical oxidation & Fuel cell & {$[50]$} \\
Oxygen plasma & Fuel cell & {$[14]$} \\
Spark discharge & Sensors & {$[51]$} \\
Gamma irradiation & Fuel cell & {$[14]$} \\
Thermal air oxidation & Fuel cell & {$[14,52,53]$} \\
Laser ablation & Sensors & {$[54]$} \\
Electrophoretic deposition and & & {$[55-57]$} \\
electrophoretic deposition & & \\
& & {$[55,56]$} \\
Carbon grafting & Metal capture & {$[55,56,58]$} \\
& Metal capture & {$[57]$} \\
\hline
\end{tabular}

oxides and other catalytic systems immobilised (chemically or chelated) have particular application in industrial applications beyond the more common fuel cell systems [56, 57]. The electrochemical pre-treatment processes investigated here provide an option through which to aid the further modification of the electrode and benefits greatly from the accessibility of the approach.

\section{Conclusions}

The modification of carbon fiber has given rise to a substantial library covering a wide variety of approaches but, as yet, there has been no study of the influence of ultrasound. Cavitation and acoustic streaming have been found to improve the kinetics of the electro-oxidation processes but it is noteworthy that there is a disparity in the relative populations of the various carbon-oxygen functionalities generated at the surface compared to silent oxidation. A possible explanation could be attributed to the physical damage occurring at the fiber interface. A significant finding is that the proportion of carboxylic acid groups is not particularly significant and this could have ramifications for subsequent modification steps-particularly those seeking to covalently bind catalytic species to the fiber.

Acknowledgements The authors are pleased to acknowledge financial support from the European Union's INTERREG VA Programme, managed by the Special EU Programmes Body (SEUPB) and the Department for the Economy (DfE) Northern Ireland, and Kimal PLC.

Open Access This article is licensed under a Creative Commons Attribution 4.0 International License, which permits use, sharing, adaptation, distribution and reproduction in any medium or format, as long as you give appropriate credit to the original author(s) and the source, provide a link to the Creative Commons licence, and indicate if changes were made. The images or other third party material in this article are included in the article's Creative Commons licence, unless indicated 
otherwise in a credit line to the material. If material is not included in the article's Creative Commons licence and your intended use is not permitted by statutory regulation or exceeds the permitted use, you will need to obtain permission directly from the copyright holder. To view a copy of this licence, visit http://creativecommons.org/licenses/by/4.0/.

\section{References}

1. Alkire R, Bartlett P (2015) Electrochemistry of carbon electrodes-advances in electrochemical sciences and engineering. Wiley, New York

2. Blyth RIR, Buqa H, Netzer FP et al (2001) X-ray photoemission studies of surface pre-treated graphite electrodes. J Power Sources 97-98:171-173. https://doi.org/10.1016/S0378-7753(01)00540-7

3. McClure JP, Jiang R, Chu D, Fedkiw PS (2014) Oxygen electroreduction on Fe-or Co-containing carbon fibers. Carbon N Y 79:457-469. https://doi.org/10.1016/j.carbon.2014.08.005

4. Feng Y, Yang Q, Wang X, Logan BE (2010) Treatment of carbon fiber brush anodes for improving power generation in air-cathode microbial fuel cells. J Power Sources 195:1841-1844. https://doi. org/10.1016/j.jpowsour.2009.10.030

5. Oickle AM, Tom J, Andreas HA (2016) Carbon oxidation and its influence on self-discharge in aqueous electrochemical capacitors. Carbon N Y 110:232-242. https://doi.org/10.1016/j.carbo n.2016.09.011

6. Zhang Z, Xi J, Zhou H, Qiu X (2016) KOH etched graphite felt with improved wettability and activity for vanadium flow batteries. Electrochim Acta 218:15-23. https://doi.org/10.1016/j.elect acta.2016.09.099

7. Pan Z, Wang K, Wang Y et al (2018) In-situ electrosynthesis of hydrogen peroxide and wastewater treatment application: a novel strategy for graphite felt activation. Appl Catal B 237:392-400. https://doi.org/10.1016/j.apcatb.2018.05.079

8. Wang Y, Liu Y, Wang K et al (2015) Preparation and characterization of a novel $\mathrm{KOH}$ activated graphite felt cathode for the electro-Fenton process. Appl Catal B 165:360-368. https://doi. org/10.1016/j.apcatb.2014.09.074

9. Ahn HJ, Lee JH, Jeong Y et al (2007) Nanostructured carbon cloth electrode for desalination from aqueous solutions. Mater Sci Eng A 448-451:841-845. https://doi.org/10.1016/j.msea.2006.02.448

10. Miao J, Zhu H, Tang Y et al (2014) Graphite felt electrochemically modified in $\mathrm{H}_{2} \mathrm{SO}_{4}$ solution used as a cathode to produce $\mathrm{H}_{2} \mathrm{O}_{2}$ for pre-oxidation of drinking water. Chem Eng J 250:312-318. https ://doi.org/10.1016/j.cej.2014.03.043

11. Bigham T, Casimero C, Dooley JSG et al (2019) Microbial water quality: Voltammetric detection of coliforms based on riboflavinferrocyanide redox couples. Electrochem commun 101:99-103. https://doi.org/10.1016/j.elecom.2019.02.022

12. Casimero C, McConville A, Fearon JJ et al (2018) Sensor systems for bacterial reactors: A new flavin-phenol composite film for the in situ voltammetric measurement of $\mathrm{pH}$. Anal Chim Acta 1027:1-8. https://doi.org/10.1016/j.aca.2018.04.053

13. Pereira AR, de Souza JCP, Iost RM et al (2016) Application of carbon fibers to flexible enzyme electrodes. J Electroanal Chem 780:396-406. https://doi.org/10.1016/j.jelechem.2016.01.004

14. Mao X, Tian W, Hatton TA, Rutledge GC (2016) Advances in electrospun carbon fiber-based electrochemical sensing platforms for bioanalytical applications. Anal Bioanal Chem 408:13071326. https://doi.org/10.1007/s00216-015-9209-x

15. Choi D, Kil HS, Lee S (2019) Fabrication of low-cost carbon fibers using economical precursors and advanced processing technologies. Carbon N Y 142:610-649. https://doi.org/10.1016/j.carbo n.2018.10.028
16. Yao SS, Jin FL, Rhee KY et al (2018) Recent advances in carbonfiber-reinforced thermoplastic composites: a review. Composite B 142:241-250. https://doi.org/10.1016/j.compositesb.2017.12.007

17. Ogale AA, Zhang M, Jin J (2016) Recent advances in carbon fibers derived from biobased precursors. J Appl Polym Sci 133:43794. https://doi.org/10.1002/app.44212

18. Huang X (2009) Fabrication and properties of carbon fibers. Materials (Basel) 2:2369-2403. https://doi.org/10.3390/ma2042369

19. Sharma M, Gao S, Mäder E et al (2014) Carbon fiber surfaces and composite interphases. Compos Sci Technol 102:35-50. https:// doi.org/10.1016/j.compscitech.2014.07.005

20. Tiwari S, Bijwe J (2014) Surface treatment of carbon fibers-a review. Procedia Technol 14:505-512. https://doi.org/10.1016/j. protcy.2014.08.064

21. Morgan P (2005) Carbon fibers and their composites. Taylor \& Francis, Boca Raton

22. Chung DDL (2017) Carbon composites: composites with carbon fibers, nanofibers, and nanotubes. Butterworth-Heinemann, Kidlington

23. Százdi L, Gulyás J, Pukánszky B (2002) Electrochemical oxidation of carbon fibres: adsorption of the electrolyte and its effect on interfacial adhesion. Composite A 33:1361-1365. https:// doi.org/10.1016/S1359-835X(02)00148-3

24. Yuan H, Wang C, Zhang S, Lin X (2012) Corrigendum to 'Effect of surface modification on carbon fiber and its reinforced phenolic matrix composite'. Appl Surf Sci 259:902. https://doi. org/10.1016/j.apsusc.2012.10.034

25. Woodhead AL, de Souza ML, Church JS (2017) An investigation into the surface heterogeneity of nitric acid oxidized carbon fiber. Appl Surf Sci 401:79-88. https://doi.org/10.1016/j.apsus c. 2016.12 .218

26. Kahoush M, Behary N, Cayla A et al (2019) Surface modification of carbon felt by cold remote plasma for glucose oxidase enzyme immobilization. Appl Surf Sci 476:1016-1024. https:// doi.org/10.1016/j.apsusc.2019.01.155

27. Almeida DAL, Couto AB, Oishi SS, Ferreira NG (2018) Chemical and electrochemical treatment effects on the morphology, structure, and electrochemical performance of carbon fiber with different graphitization indexes. J Solid State Electrochem 22:3493-3505. https://doi.org/10.1007/s10008-018-4037-5

28. Prasad K, Muthuraman G, Zen JM (2008) The role of oxygen functionalities and edge plane sites on screen-printed carbon electrodes for simultaneous determination of dopamine, uric acid and ascorbic acid. Electrochem Commun 10:559-563. https ://doi.org/10.1016/j.elecom.2008.01.033

29. Matos I, Bernardo M, Fonseca I (2017) Porous carbon: A versatile material for catalysis. Catal Today 285:194-203. https:// doi.org/10.1016/j.cattod.2017.01.039

30. Boehm H (2002) Surface oxides on carbon and their analysis: a critical assessment. Carbon N Y 40:145-149. https://doi. org/10.1016/s0008-6223(01)00165-8

31. Kim NH, Mishra AK, Lee JH et al (2012) Chemical functionalization of graphene and its applications. Prog Mater Sci 57:1061-1105. https://doi.org/10.1016/j.pmatsci.2012.03.002

32. Compton R, Eklund J, Marken F (1997) Sonoelectrochemical processes: a review. Electroanalysis 9:509-522

33. González-García J, Esclapez MD, Bonete P et al (2010) Current topics on sonoelectrochemistry. Ultrasonics 50:318-322. https ://doi.org/10.1016/j.ultras.2009.09.022

34. Xie J, Ding J, Attenburrow G, Mason T (1999) Influence of power ultrasound on leather processing. Part I: Dyeing. J Am Leather Chem Assoc 94:146-157

35. Murphy MA, Marken F, Mocak J (2003) Sonoelectrochemistry of molecular and colloidal redox systems at carbon nanofiberceramic composite electrodes. Electrochim Acta 48:3411-3417. https://doi.org/10.1016/S0013-4686(03)00390-6 
36. Liu J, Tian Y, Chen Y et al (2010) A surface treatment technique of electrochemical oxidation to simultaneously improve the interfacial bonding strength and the tensile strength of PANbased carbon fibers. Mater Chem Phys 122:548-555. https://doi. org/10.1016/j.matchemphys.2010.03.045

37. Banks C, Davies T, Wildgoose G, Compton R (2005) Electrocatalysis at graphite and carbon nanotube modified electrodes: edge-plane sites and tube ends are the reactive sites. Chem Commun. https://doi.org/10.1039/B413177K

38. Hyde M, Davies T, Compton R (2005) Fabrication of random assemblies of mEtal nanobands: a general method. Angew Chemie-International Ed 44:6491-6496

39. Cline K, McDermott M, McCreery R (1994) Anomalously slowelectron transfer at ordered graphite-electrodes-influence of electronic factors and reactive sites. J Phys Chem 98:5314-5319

40. McDermott C, Kneten K, McCreery R (1993) ELECTRONtransfer kinetics of aquated $\mathrm{Fe}+3 /+2, \mathrm{Eu}+3 /+2$, and $\mathrm{V}+3 /+2$ at carbon electrodes-inner-sphere catalysis by surface oxides. J Electrochem Soc 140:2593-2599

41. Ranganathan S, Kuo T, McCreery R (1999) Facile preparation of active glassy carbon electrodes with activated carbon and organic solvents. Anal Chem 71:3574-3580

42. Xiong L, Batchelor-Mcauley C, Ward KR et al (2011) Voltammetry at graphite electrodes: The oxidation of hexacyanoferrate (II) (ferrocyanide) does not exhibit pure outer-sphere electron transfer kinetics and is sensitive to pre-exposure of the electrode to organic solvents. J Electroanal Chem 661:144-149. https://doi. org/10.1016/j.jelechem.2011.07.028

43. Ji X, Banks CE, Crossley A, Compton RG (2006) Oxygenated edge plane sites slow the electron transfer of the ferro-/ferricyanide redox couple at graphite electrodes. ChemPhysChem 7:13371344. https://doi.org/10.1002/cphc. 200600098

44. Chou A, Bocking T, Singh N, Gooding J (2005) Demonstration of the importance of oxygenated species at the ends of carbon nanotubes for their favourable electrochemical properties. Chem Commun. https://doi.org/10.1039/B415051A

45. Banks C, Moore R, Davis TJ, Compton R (2004) Investigation of modified basal plane pyrolytic graphite electrodes: definitive evidence for the electrocatalytic properties of the ends of carbon nanotubes. Chem Commun. https://doi.org/10.1039/B406174H

46. Zhang G, Sun S, Yang D et al (2008) The surface analytical characterization of carbon fibers functionalized by $\mathrm{H}_{2} \mathrm{SO}_{4} / \mathrm{HNO}_{3}$ treatment. Carbon N Y 46:196-205. https://doi.org/10.1016/j.carbo n.2007.11.002

47. Bismarck A, Kumru ME, Springer J, Simitzis J (1999) Surface properties of PAN-based carbon fibers tuned by anodic oxidation in different alkaline electrolyte systems. Appl Surf Sci 143:45-55. https://doi.org/10.1016/S0169-4332(98)00929-5

48. Anderson A, Phair J, Benson J et al (2014) Investigating the use of endogenous quinoid moieties on carbon fibre as means of developing micro pH sensors. Mater Sci Eng C 43:533-537. https://doi.org/10.1016/j.msec.2014.07.038

49. Mohammadzadeh Kakhki R (2019) A review to recent developments in modification of carbon fiber electrodes. Arab J Chem 12:1783-1794. https://doi.org/10.1016/j.arabjc.2014.11.058

50. Yue L, Li W, Sun F et al (2010) Highly hydroxylated carbon fibres as electrode materials of all-vanadium redox flow battery. Carbon N Y 48:3079-3090. https://doi.org/10.1016/j.carbon.2010.04.044

51. Bartosova Z, Riman D, Halouzka V et al (2016) A comparison of electrochemically pre-treated and spark-platinized carbon fiber microelectrode. Measurement of 8-oxo-7,8-dihydro-2' deoxyguanosine in human urine and plasma. Anal Chim Acta 935:82-89. https://doi.org/10.1016/j.aca.2016.06.044

52. Ghimire PC, Schweiss R, Scherer GG et al (2019) Optimization of thermal oxidation of electrodes for the performance enhancement in all-vanadium redox flow battery. Carbon N Y 155:176-185. https://doi.org/10.1016/j.carbon.2019.08.068

53. Greco KV, Forner-Cuenca A, Mularczyk A et al (2018) Elucidating the nuanced effects of thermal pretreatment on carbon paper electrodes for vanadium redox flow batteries. ACS Appl Mater Interfaces 10:44430-44442. https://doi.org/10.1021/acsami.8b157 93

54. Ezekiel HB, Sharp D, Villalba MM, Davis J (2008) Laser-anodised carbon fibre: coupled activation and patterning of sensor substrates. J Phys Chem Solids. https://doi.org/10.1016/j. jpcs.2008.06.137

55. Jin GP, Wang XL, Fu Y, Do Y (2012) Preparation of tetraoxalyl ethylenediamine melamine resin grafted-carbon fibers for nanonickel recovery from spent electroless nickel plating baths. Chem Eng J 203:440-446. https://doi.org/10.1016/j.cej.2012.07.055

56. Su JY, Jin GP, Chen T et al (2017) The characterization and application of prussian blue at graphene coated carbon fibers in a separated adsorption and electrically switched ion exchange desorption processes of cesium. Electrochim Acta 230:399-406. https://doi. org/10.1016/j.electacta.2017.02.027

57. Peng SY, Jin GP, Cui JS et al (2018) Preparation of nickel hexacyanoferrate/heterogeneous carbon composites for $\mathrm{CO}_{2}$ continuous electrocatalytic reduction to formic acid. J Environ Chem Eng 6:6931-6938. https://doi.org/10.1016/j.jece.2018.10.052

58. Lu L, Liang L, Teh KS et al (2017) The electrochemical behavior of carbon fiber microelectrodes modified with carbon nanotubes using a two-step electroless plating/chemical vapor deposition process. Sensors (Switzerland). https://doi.org/10.3390/s1704 0725

Publisher's Note Springer Nature remains neutral with regard to jurisdictional claims in published maps and institutional affiliations. 